\title{
Integrated Reporting
}



Cristiano Busco - Mark L. Frigo Angelo Riccaboni - Paolo Quattrone Editors

\section{Integrated Reporting \\ Concepts and Cases that Redefine Corporate Accountability}

Foreword by Sabina Ratti

筮 Springer 


\section{Editors}

Cristiano Busco

J.E. Cairnes School of Business

\& Economics

National University of Ireland

Galway

Ireland

Angelo Riccaboni

University of Siena

Siena

Italy
Mark L. Frigo

Kellstadt Graduate School of Business

DePaul University

Chicago

Illinois

USA

Paolo Quattrone

The University of Edinburgh

Edinburgh

United Kingdom

This publication was grant-aided by the Publications Fund of National University of Ireland Galway / Rinneadh maoiniú ar an bhfoilseachán seo trí Chiste Foilseachán Ollscoil na hÉireann, Gaillimh

ISBN 978-3-319-02167-6

ISBN 978-3-319-02168-3 (eBook)

DOI 10.1007/978-3-319-02168-3

Springer Cham Heidelberg New York Dordrecht London

Library of Congress Control Number: 2013954808

(C) Springer International Publishing Switzerland 2013

This work is subject to copyright. All rights are reserved by the Publisher, whether the whole or part of the material is concerned, specifically the rights of translation, reprinting, reuse of illustrations, recitation, broadcasting, reproduction on microfilms or in any other physical way, and transmission or information storage and retrieval, electronic adaptation, computer software, or by similar or dissimilar methodology now known or hereafter developed. Exempted from this legal reservation are brief excerpts in connection with reviews or scholarly analysis or material supplied specifically for the purpose of being entered and executed on a computer system, for exclusive use by the purchaser of the work. Duplication of this publication or parts thereof is permitted only under the provisions of the Copyright Law of the Publisher's location, in its current version, and permission for use must always be obtained from Springer. Permissions for use may be obtained through RightsLink at the Copyright Clearance Center. Violations are liable to prosecution under the respective Copyright Law.

The use of general descriptive names, registered names, trademarks, service marks, etc. in this publication does not imply, even in the absence of a specific statement, that such names are exempt from the relevant protective laws and regulations and therefore free for general use.

While the advice and information in this book are believed to be true and accurate at the date of publication, neither the authors nor the editors nor the publisher can accept any legal responsibility for any errors or omissions that may be made. The publisher makes no warranty, express or implied, with respect to the material contained herein.

Printed on acid-free paper

Springer is part of Springer Science+Business Media (www.springer.com) 


\section{Foreword}

Integrated Reporting is arguably the current frontier of corporate reporting. The demands on corporate reports are growing rapidly in parallel with stakeholder engagement of a greater in-depth understanding of the companies they have an interest in. In this context, the recent establishment of the International Integrated Reporting Council by a number of leading organizations represented an additional, perhaps decisive, move towards the definition of a globally accepted reporting framework. Such a framework aims to bring together financial, environmental, social and governance information to enable stakeholders understand the true ability of a company to deliver sustainable value and to educate investors to overcome short-termism in their investment decisions. This, in turn, would further enhance a company's ability to make sustainable choices.

The definition of such a framework is everything but easy, though. This is because corporate numbers and information are quite meaningless without a proper and full understanding of the complex context which generates them. Let me draw a comparison with the act of watching a movie. If you watch the last $10 \mathrm{~min}$ of a movie you most likely know how the movie ends, you are aware of its final outcomes. If this is a romantic movie, you know if the two are still together or not; while, in the case of an action movie, you most likely end up discovering who the killer was. But, unfortunately, although you do get to see the final outcomes of the movie, you still miss a lot to make sense of it. You miss a full appreciation of the themes of the movie, its significant passage points and the unique and possibly complex story that has led to this specific final outcome. When you approach most of contemporary corporate reports, the feeling is similar to the one described above: it is difficult to fully understand how a number of different, and often stand alone, indicators have contributed to value creation; it is difficult to appreciate the complexity hidden behind the numbers. Ultimately, in most of the cases it is difficult to infer how sustainable value creation can be maintained and further developed in the future. Integrated Reporting aims to do that!

Because the efforts around Integrated Reporting are still in their early stages, I really do welcome this edited collection on the topic. When I have read the contents of this book, this has brought me back to my early days at Eni where, 
although my background is molecular biology, I was leading a project tailored to develop an early form of environmental accounting, as well as to identify a control system for evaluating the impact of business operations on the environment. I was working with an interdisciplinary team in search of metrics, solutions and data that would have eventually allowed the company to perform more efficiently in environmental protection, make savings and better understand its business. This experience has been extremely important for us at Eni. It allowed us to practice collaboration across disciplines and integrated thinking. This first step was mainly an internal effort, though. When, later on, we succeeded in incorporating the results of the dialogue with our external stakeholders, environmental and social reporting at Eni moved to the next level.

Stakeholders engagement has been of paramount importance in the evolution of corporate reporting. Systematic engagement with key stakeholders has enabled corporations to question, and then challenge, a number of things that possibly had been taken for granted before that. At Eni, after having issued a series of Environmental and then Sustainability Reports we realized that, although the numbers were allowing a true and fair review of the company's performance, operations and management, they were not necessarily relevant to the stakeholders or able to hint the sustainability of the business. Neither was the simple act of reporting data relevant per se. What was missing was a broader process of analysis and communication able to put performance in context, able to represent the strategic leverages the company was using to build and maintain its ability to produce value in the long term. Stakeholders' demands for greater transparency have, in time, been coupled with an internal reflection on what the company considered its strategic drivers: nowadays, our integrated reporting aims to respond to this challenge.

A cultural shift is, though, required to support such a process. A shift of paradigm rooted on the reorganization of systems, processes and practices in search of Sustainable Value creation and representation. In this respect, joining the Pilot Programme of the International Integrated Reporting Council back in 2011 was very useful to us. Integrated Reporting offers an opportunity to combine Sustainability and profitability in a single process, in a single document and, ultimately, in a single story. It is a promising powerful tool to increase the internal and external awareness, especially among investors, on the way in which the integrated management of the business is currently practiced.

Significantly, Integrated Reporting aims at offering a long-term view. It is a dynamic observatory designed and implemented to offer a space where organizational strategies, objectives, results and outcomes can be illustrated and interpreted in a combined fashion. The objective is not so much to unpack complexity, rather to make the users appreciate how the constitutive elements of a complex organization in a complex environment contribute to Sustainable Value creation over the short, medium and long term. In doing so, the numbers and information provided in the Integrated Report aim at representing the way in which Sustainability's objectives and multiple perspectives are fully embedded within the Company's business model and decision-making processes. 
For the above-mentioned reasons, I do welcome the publication of this book. Integrated Reporting is in its early stages, and any effort to illustrate, discuss and eventually question its contents, elements and principles is a much needed and useful exercise. Integrated Reporting is currently a lively and engaging theme, worthwhile to be further explored both theoretically and practically around the globe. Along this line, the usefulness of this book is twofold. First, it provides a number of insightful chapters attempting to deepen our understanding on specific concepts and principles. Second, this book offers a collection of best practices attempting to describe and, in some cases, discuss how a number of companies, large and small, private or public, are approaching Integrated Reporting in practice.

The trajectory of Integrated Reporting is about to mark an important milestone. Soon, in December, the International Integrated Reporting Council will release the first version of its framework. The journey has just recently begun, but Integrated Reporting is about to enter in a critical phase where its rationale as well as its concept will be tested, challenged and advanced.

This book is very timely and prepares all of us to do that. I trust you will enjoy and benefit from reading it.

Sabina Ratti

Eni

Sustainability Senior Vice President 



\section{Introduction}

What is Integrated Reporting? Who is driving the agenda? What are the building blocks and best practices to date? This book aims to address these questions by illustrating and debating the rise of and the challenges ahead for this new form of reporting. The purpose is to participate to the current debate on Integrated Reporting (IR) by reflecting both on the key concepts, elements and principles that underpin its adoption and on a collection of cases that describe how a number of companies, large and small, private and public, are approaching IR in practice.

What is Integrated Reporting? IR is a process that results in communicatingthrough the annual integrated report—value creation over time. According to the International Integrated Reporting Council (IIRC), an integrated report is a concise communication about how an organization's strategy, governance, performance and prospects, in the context of its external environment, lead to the creation of value over the short, medium and long term. Although providers of financial capital are the primary intended IR users, an integrated report should be designed to benefit all stakeholders-including employees, customers, suppliers, business partners, local communities, regulators and policy makers-interested in an organization's ability to create value over time. The key objective of IR is to enhance accountability and stewardship with respect to the broad base of six kinds of capital, or "capitals" (financial, manufactured, intellectual, human, social and relationship and natural), and promote understanding of their interdependencies. In doing this, IR is designed to support integrated thinking, decision making and actions that focus on sustainable value creation for stakeholders.

Who is driving the agenda? Although the journey of IR has started much earlier than that, 3 years have now gone by since a number of leading organizations, including the Prince's Accounting for Sustainability Project and the Global Reporting Initiative, announced the formation of the International Integrated Reporting Council (IIRC). During these years the IIRC, a global coalition of regulators, investors, companies, standards setters, the accounting profession and nongovernmental organizations, has actively operated to redesign the landscape of corporate reporting. In April 2013, the IIRC released a Consultation Draft (CD) of the first Integrated Reporting Framework. The CD focuses on how to prepare and present an integrated report and what to include in it. The CD was developed based 
on an analysis of the responses to the 2011 Discussion Paper "Towards Integrated Reporting - Communicating Value in the 21st Century", the publication of a draft outline in July 2012, and a Prototype Framework in November 2012. Importantly, the first version of its IR Framework is expected to be released by the IIRC in December 2013.

What are the building blocks and best practices to date? The CD released by the IIRC introduces and discusses a number of fundamental concepts, content elements and guiding principles for the implementation of IR. The fundamental concepts of IR are represented by the capitals that an organization uses and affects, the organization's business model and the creation of value over time. The business model is the vehicle through which an organization creates value. That value is embodied in the capitals-sometimes also referred to as resources and relationships - that the organization uses and affects. The assessment of an organization's ability to create value in the short, medium and long term depends on an understanding of the connectivity between its business model and a wide range of internal and external factors.

These factors represent the content elements of the integrated report. An integrated report is built around seven elements that define its content and communicate the organization's unique value-creation story. According to the $\mathrm{CD}$ these elements are organizational overview and external environment, governance, opportunities and risks, strategy and resource allocation, business model, performance and future outlook. By linking contents across these elements, an integrated report can build the story of the business from a basic description of the business model through the external factors affecting the business and management's strategy for dealing with them and developing the business. This provides a foundation from which to discuss the performance, prospects and governance of the business in a way that focuses on its most important aspects.

Because its intention is to offer an appropriate balance between flexibility and prescription, the IR Framework is principles based rather than being founded on a more rigid, rules-based approach. The idea is to recognize the wide variation in individual circumstances of different organizations yet, at the same time, to enable a sufficient degree of comparability across organizations to meet relevant information needs. For this reason, the IR Framework doesn't focus on rules for measurement, disclosure of individual matters or even the identification of specific key performance indicators. Rather, the framework is driven by integrated thinking, which, as illustrated in the $\mathrm{CD}$, should lead to integrated decision making and execution towards the creation of value. The purpose of this approach is to stimulate the active consideration by organizations of the relationships between their various operating and functional units and the kinds of capital that they use and have an effect on. The CD introduces and recommends six guiding principles, which underpin the preparation of an IR, inform its content and affect how information is presented. The six principles are strategic focus and future orientation, connectivity of information, stakeholder responsiveness, materiality and conciseness, reliability and completeness, consistency and comparability. 
Part one of the book includes a series of chapters reflecting on some of the key concepts, elements and principles that underpin IR adoption and that are introduced in more details in Chap. 1. In particular, after having reviewed the concept of sustainability (Chap. 2) and the recent trends in corporate reporting (Chap. 3), a number of guiding principles are then explored in the following chapters. These principles are connectivity of information (Chap. 4), materiality (Chap. 5) and stakeholder engagement (Chap. 6). Next, the book further analyse some of the most significant content elements of IR. In particular, Chap. 7 focuses on the interplay between strategy and the business model, Chap. 8 on performance measurement and the capitals, Chap. 9 on value creation and cost management, and Chap. 10 integrated risk management. Finally, Chap. 11 introduces a proposal of value added calculation within the context of multinational enterprises, and Chap. 12 offers some reflections concerning the adoption of IR in the Public Sector.

Part two of the book presents a collection of cases that describe how a number of companies, large and small, private and public, are approaching IR in practice. There is no particular reason that justifies the sequence of the chapters. Cases are focused on the following Companies: Eni (Chap. 13), Enel (Chap. 14), Vodacom Group (Chap. 15), Smithfield (Chap. 16), Monnalisa (Chap. 17), Eskom (Chap. 18), HERA (Chap. 19) and finally, the Auditor General of South Africa (Chap. 20). Although the adoption of IR (or similar form of reporting) by these companies is not comparable since each one of them has its own story, motivation and trajectory, all of these companies represent examples of organizations that are currently questioning traditional form of reporting to move towards an integrated way to communicate the story of sustainable value creation.

We would like to thank all the authors of the book chapters: without your enthusiasm and commitment this book simply would have not been possible. Our gratitude also goes to Dr. Sabina Ratti, Sustainability Senior Vice President at Eni, who has been so kind to take care of the foreword of this book.

Finally, we wish to acknowledge the precious support of Elena Giovannoni, Loredana Smaldore and Fabrizio Granà, who have contributed to the editing process of the book.

We trust you will enjoy the reading!

August 2013

Cristiano Busco

Mark L. Frigo

Paolo Quattrone

Angelo Riccaboni 



\section{Contents}

\section{Part I Introduction}

1 Towards Integrated Reporting: Concepts, Elements and Principles ....................... 3

Cristiano Busco, Mark L. Frigo, Paolo Quattrone, and Angelo Riccaboni

Part II Review of Key Principles, Concepts and Elements for Integrated Reporting

2 What Is Sustainability? A Review of the Concept and Its Applications

Elena Giovannoni and Giacomo Fabietti

3 Annual Reports, Sustainability Reports and Integrated Reports: Trends in Corporate Disclosure . . . . . . . . . . . . . . 4 Marco Fasan

4 The Connectivity of Information for the Integrated Reporting . . . 59 Sergio Paternostro

5 Materiality and Assurance: Building the Link . . . . . . . . . . . 79 Chiara Mio

6 Stakeholder Engagement $\ldots \ldots \ldots \ldots \ldots \ldots \ldots \ldots$ Leonardo Rinaldi

7 "Integrating" Business Model and Strategy . . . . . . . . . . . . . 111 Federico Barnabè and Maria Cleofe Giorgino

8 Performance Measurement and Capitals . . . . . . . . . . . . . . . . 127 Monica Bartolini, Fabio Santini, and Riccardo Silvi

9 Integrated Reporting and Value-Based Cost Management:

A Natural Union . . . . . . . . . . . . . . . . . . . . . . . . . . . . . . . . . 147

Carol J. McNair-Connolly, Riccardo Silvi, and Monica Bartolini 
10 Approaching Risk Management from a New Integrated

Perspective . . . . . . . . . . . . . . . . . . . . . . . . . 159

Sonia Quarchioni and Francesca Trovarelli

11 The Relationship Between Multinational Enterprises and Territory in the Integrated Reporting . . . . . . . . . . . . . . . . . . 171

Christian Cavazzoni and Francesco Orlandi

12 Towards Integrated Reporting in the Public Sector

Luca Bartocci and Francesca Picciaia

Part III Towards Integrated Reporting: Cases and Best Practices

13 The Case of Eni . . . . . . . . . . . . . . . . . . . . . . . . . . . . 207

Domenica Di Donato, Raffaella Bordogna, and Cristiano Busco

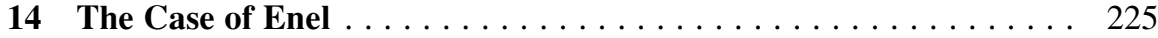

Chiara Mio and Marco Fasan

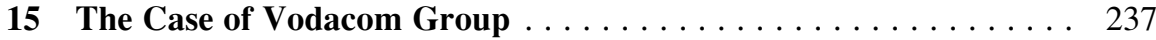

Fabrizio Granà and Libero Mario Mari

16 The Case of Smithfield Foods . . . . . . . . . . . . . . . . . . . . . 255

Loredana G. Smaldore and Christian Cavazzoni

17 The Case of Monnalisa . . . . . . . . . . . . . . . . . . . . . . . . . . . 275

Cristiano Busco, Maria Pia Maraghini, and Sara Tommasiello

18 The Case of Eskom . . . . . . . . . . . . . . . . . . . . . . . 297

Fabrizio Granà and Francesca Ceccacci

19 The Case of HERA . . . . . . . . . . . . . . . . . 313

Pasquale Ruggiero and Patrizio Monfardini

20 The Case of the Auditor-General of South Africa . . . . . . . . . . . 331 Luca Bartocci and Francesca Picciaia

List of Contributors . . . . . . . . . . . . . . . . . . . . . . . . . . . . . . 347 